\title{
LIBERTAD ACADEMICA Y RESPONSABILIDAD
}

Prof. Dr. Lautaro Ríos A.

Facultad de Derecho y Ciencias Sociales

Escuela de Derecho - Universidad de Valparaíso.

Quienes venimos a la Universidad a enseñar, a investigar o a difundir el saber, estamos ejercitando, al mismo tiempo, un derecho o -más exactamente- un conjunto de derechos que nos habilitan para desempeñar cabalmente nuestra misión universitaria.

Quienes vienen a adquirir conocimientos, aptitudes y destrezas, esto es, a formarse como universitarios, también están dotados -aunque a veces lo ignoren- de ciertas garantías que, junto con resguardar la calidad de su aprendizaje, dignifican su advenimiento a la educación superior.

A este estatuto propio de los académicos y de los estudiantes se le conoce con la denominación genérica de Libertad Académica (L.A.). No es ella, por lo tanto, un atributo exclusivo de los maestros sino también de los alumnos y -nos atrevemos a decir- una cualidad esencial del clima universitario.

Como todo derecho, la libertad académica conlleva una responsabilidad ineludible que la sigue como la sombra al cuerpo.

A estas dos nociones inseparables -libertad y responsabilidad- pretendemos referirnos justamente cuando se inicia un nuevo año lectivo, cuando los profesores renuevan su vocación de servicio, y cuando muchos estudiantes, con la esperanza marcada en sus rostros, ingresan por vez primera a la Universidad.

\section{CONCEPTO DE LA LIBERTAD ACADEMICA.}

Como una primera aproximación observamos que la L.A. no es una herramienta que necesitemos usar en todo momento ni en todas las fases del quehacer universitario.

Puede concebirse la enseñanza de muchas materias -y hasta de disciplinas completas- sin la comparecencia de esta libertad. Es más, ante aquellas proposiciones científicas reiterada y universalmente demostradas como verdaderas, no juega una L.A. que sólo va a adquirir importancia desde el instante en que el conocimiento que se imparte carezca de rigurosa exactitud o de universal aceptación, y en la medida en que varíen sus alternativas probablemente verdaderas.

* Discurso inaugural del año académico en el $84^{\circ}$ Aniversario de la Escuela de Derecho. (Abril- 1995). 
Sería posible argüir que, aún en esos casos, la L.A. puede manifestarse en la metodología de la investigación o de la enseñanza; o en el sistema pedagógico que el profesor resuelva utilizar.

Sin embargo, reconociendo que ella también alcanza a esas modalidades de la actividad universitaria, puntualicemos que no es allí donde su alto relieve se pone de manifiesto, sino en el campo de las ideas alternativas, de las teorías diversas o contrarias existentes sobre un objeto del saber. Para decirlo de manera clara y sencilla, ella se traduce en el ejercicio pleno, dentro de la Universidad, de las libertades de enseñanza, de opinión y de expresión, así como de su corolario, el derecho a la discrepancia.

Nuestra Ley General sobre Universidades señala que "La libertad académica incluye la facultad de abrir, organizar y mantener establecimientos educacionales, cumpliendo los requisitos establecidos por la ley, y la de buscar y enseñar la verdad conforme con los cánones de la razón y de los métodos de la ciencia". (DFL. N 1-1980 Educación).

Para los efectos de esta exposición, definiremos la Libertad Académica como la facultad que tienen los docentes e investigadores de profesar todas las hipótesis, las teorías alternativas, las doctrinas o las escuelas existentes sobre una determinada materia y también para exponer su propia idea o posición; así como el derecho de los estudiantes para adherir a aquella opinión, corriente o idea que consideren verdadera o más probable, aunque no sean las que su maestro profesa, o para no adherir a ninguna y expresar las propias.

\section{LIMITACIONES DE LA LIBERTAD ACADEMICA}

Todo ejercicio de libertades reconoce limitaciones. No escapa a esta regla la L.A.. Ella no faculta al maestro para enseñar lo que se le antoje, sino para enseñar lo que DEBE enseñar. - ¿Qué limitaciones pone, pues, a la L.A. lo que se debe enseñar?

1. PROGRAMA. Aunque el orden de aparición de las limitaciones no sea prioritario, no cabe duda que la más concreta y perentoria la constituye el Programa del curso que se imparte o de la investigación que se aborda.

El tiempo -se ha dicho de él que es un tirano implacable- fuerza al profesor a constreñir y encuadrar su caudal de conocimiento, su ritmo, y hasta la altura del vuelo de sus clases, al itinerario y contenido, generalmente recargado, del Programa.

De allí que sea muy importante la atención que presten los académicos a la elaboración del programa de su asignatura. Porque, a mayor detalle, tal vez haya mayor precisión de los contenidos docentes; pero también habrá, con toda certeza, menor libertad en la personal contribución de cada profesor a la formación del estudiante, lo cual está en la esencia del proceso educativo y no siempre se consulta en tales programas ${ }^{158}$.

2. El carácter de la Universidad.- Cuando hablamos del carácter de la Universidad no nos estamos refiriendo ni a su fisonomía profesional -humanística, científica o técnica-

${ }^{158}$ Es común en algunas universidades europeas que el Programa sólo contenga un listado de materias cuyo entero desarrollo se deja a cada profesor, quien elabora su propio Programa. 
ni a su perfil académico, ni a sus tradiciones; sino, en el sentido griego de la expresión, a lo grabado en ella que -a su vez- ella es capaz de grabar en todos sus miembros.

Hablamos de ese peculiar modo de ser de cada Universidad que la hace inconfundible y la diferencia de las demás; modo de ser que se inculca y que llevamos, como un nuevo parentesco, impreso para siempre; nos estamos refiriendo al Alma Mater de la Universidad.

Pues bien, en la institución llamada a ser cuna, crisol y fermento de las ideas, lo que define este carácter es su contenido ideológico. Este contenido puede ser confesional, puede ser pluralista y hasta puede ser neutro.

La restricción que este carácter de la Universidad impone a la L.A., es que ella no puede negarlo ni contradecirlo.

El carácter de la Universidad no sólo se manifiesta en su definición ideológica y en el contenido y orientación de sus programas; se expresa también a través del cuerpo académico que ella misma ha escogido para imprimirlo en sus educandos.

Un profesor no puede introducir subrepticiamente en su cátedra, ideas de contrabando. No puede traicionar la confianza que en él depositó la Universidad al investirle de la dignidad académica, tergiversando la orientación formadora que su carácter persigue.

La transmisión de este carácter exige coherencia. El término "educación" deriva de la voz latina "educere"; conducir hacia. De allí que deba procurarse que tanto el trayecto como el resultado de la educación universitaria sean coherentes. ${ }^{159}$

Esta coherencia de que hablamos, conduce a una oportuna reflexión acerca del carácter comunitario de la actividad universitaria. Ya en el siglo XVIII, el insigne Rey Sabio, Alfonso $X$ definía la Universidad como "Ayuntamiento de maestros et de escolares que es fecho en algunt logar con voluntad et con entendimiento de aprender los saberes" (Las siete Partidas, P. II, tit.31). La Universidad es comunión de una tarea compartida que, para conformar un universo, requiere coherencia.

${ }^{159}$ Siempre hemos creído que el fundamento de esta limitación es de carácter ético. No obstante, y a propósito del debate parlamentario de la Ley Orgánica del Derecho a la Educación. en España, nos hemos enterado de que este problema fue regulado en este país en la Ley Org. de Centros Educacionales y que ha sido materia de decisión del Excmo. Tribunal Constitucional (T.C.). En un fallo de 1981 el T.C. estableció que la existencia de un ideario no obliga al profesor "...ni a convertirse en apologista del mismo, ni a transformar su enseñanza en propaganda ni adoctrinamiento, ni a subordinar a ese ideario las exigencias que el rigor científico impone a su labor. El profesor es libre como profesor, en el ejercicio de su actividad específica. Su libertad es, sin embargo, libertad en el puesto que ocupa, es decir, en un determinado Centro y ha de ser compatible, por tanto, con la libertad del Centro, del que forma parte el ideario. La libertad del profesor no le faculta, por tanto, para dirigir ataques abiertos o solapados contra ese ideario, sino sólo para desarrollar su actividad en los términos que juzgue más adecuados y que, con arreglo a un criterio serio y objetivo, no resulten contrarios a aquél". (T.C. s. 5; 24 11-81; BOE. № 47 DEL 24-11-81). 
La formación universitaria exige que, a pesar de que cada cátedra y cada actividad educativa se impartan segregadamente, el resultado pedagógico que se logre sea perfectamente armónico.

La cátedra no puede concebirse como una plaza de espectáculos en que cada académico despliegue, en cualquier dirección, el vuelo de su personal virtuosismo. Es más bien, la escucha sucesiva de los diversos instrumentos de una orquesta que -siendo diferentes en tono, en profundidad y en frecuencia- termina fijando en el estudiante la melodía multifónica de una partitura integrada e integradora.

De allí, también, que no siempre sea el mejor académico quien más conocimiento posee sobre determinada materia, sino aquel que sabe armonizar la disciplina que enseña con el resto de las asignaturas que se imparten y con el espíritu informador-capaz de dar forma- que procura su conjunto.

\section{El ámbito cultural circundante.}

Otra importante limitación la constituye el contexto cultural y supracultural de la comunidad a la cual la Universidad se integra.

La L.A. debe respetar ese contexto -creencias religiosas, valores éticos, principios jurídicos- de su tiempo y circunstancias históricas.

Pues, si bien la libertad académica incluye una conciencia crítica tendiente al progreso de la sociedad en que se inserta, la principal misión de la Universidad es ser receptáculo y fuente nutricia de esa cultura y no elemento desintegrador de ella. Queremos decir que el académico puede ser -y es deseable que lo sea- cuestionador de todo cuanto sea razonable cuestionable, pero nunca piedra de escándalo de su comunidad.

Cuando la Constitución chilena establece -en el art. $19 \mathrm{~N}^{\circ} 11$ - la libertad de enseñanza, advierte -en su inciso segundo- que ella "no tiene otras limitaciones que las impuestas por la Moral, las Buenas Costumbres, el Orden Público y la Seguridad Nacional". Elementos, todos ellos, que pertenecen al contexto cultural de la sociedad chilena en que esa libertad se asegura y que, por definición constitucional, importan limitaciones a esa libertad.

\section{PRERROGATIVAS DE LA LIBERTAD ACADEMICA}

La L.A. -a nuestro juicio- contiene fundamentalmente tres prerrogativas que conciernen a otras tantas categorías de sujetos de la comunidad universitaria: La libertad de cátedra, la libertad de investigación y creación y la libertad de aprendizaje. Todas ellas conllevan, además, la libertad de participar, sin discriminaciones, en los organismos universitarios y en las demás tareas -actividad interuniversitaria, publicaciones, extensión cultural- que la Universidad emprenda. ${ }^{160}$

${ }^{160}$ La Ley de Reforma Universitaria española de 25-VIII-1983 dice, en lo pertinente: "Art. 2.1. La actividad de la Universidad, así como su autonomía, se fundamentan en el principio de la libertad académica, que se manifiesta en las libertades de cátedra, de investigación y de estudio. 2. La autonomía universitaria exige y hace posible que 


\section{LA LIBERTAD DE CATEDRA}

Muy pocas Constituciones consagran específicamente este derecho y -cuando lo hacen- ello probablemente deriva de una experiencia traumática. La mayoría se refiere a las libertades de enseñanza y de expresión, en general, o bien declaran y atribuyen la libertad a las artes o a las ciencias, como si éstas fuesen sujetos capaces de reclamarla.

La Constitución española de 1978 que reconoce la libertad de enseñanza ${ }^{161}$, en la letra c) del artículo 20.1 señala: "se reconocen y protegen los siguientes derechos: c) A la libertad de cátedra".

La Constitución italiana de 1947 dice, en cambio: "El arte y la ciencia son libres, así como también su enseñanza". ${ }^{162}$

La Constitución de Alemania Federal de 1949 señala, por su parte: "El arte y la ciencia, y la investigación y la enseñanza son libres. La libertad de enseñanza no exime de la fidelidad a la Constitución". ${ }^{163}$

La Constitución portuguesa de 1976 declara: "Será libre la creación intelectual, artística y científica ${ }^{1641}$. Su art. 43 garantiza la libertad de enseñanza.

La C. Pol. de Costa Rica de 1949 declara: "La libertad de cátedra es principio fundamental de la enseñanza universitaria" 165

La Constitución colombiana de 1991, con mayor amplitud y concisión, prescribe: "El Estado garantiza las libertades de enseñanza, aprendizaje, investigación y cátedra" ${ }^{166}$. En otras palabras, garantiza la libertad académica, íntegramente.

La reciente Constitución del Perú de 1993, luego de reconocer a toda persona la libertad de creación intelectual, artística, técnica y científica, y de garantizar la libertad de enseñanza, declara: "La educación universitaria tiene como fines la formación profesional, la difusión cultural, la creación intelectual y artística y la investigación científica y tecnológica. El Estado garantiza la libertad de cátedra y rechaza la intolerencia". (9-bis).

No es libertad, aunque se disfrace con ese nombre, el dirigismo ideológico que se impone a la enseñanza, a la cultura, a la ciencia y a las artes en algunos Estados.

En este sentido, la Constitución de la U.R.S.S. de 1977, decía: "En consonancia con los fines de la educación comunista, se garantiza a los ciudadanos de la U.R.S.S. la libertad de creación científica, técnica y artística"167.

docentes, investigadores y estudiantes cumplan con sus respectivas responsabilidades en orden a la satisfaccción de las necesidades educativas, científicas y profesionales de la sociedad".

${ }^{161}$ Art. 27.1 C.E

${ }^{162}$ aRT. 33 INC. $1^{\circ} \mathrm{C}$. Pol. italiana.

${ }^{163}$ Art. 5.3.- Grundgezets.

${ }^{164}$ Art. 42.1. C.portuguesa

${ }^{165}$ Art. 87 C. Pol. de Costa Rica.

${ }^{166}$ Art. 7 C. Pol. de Colombia.

${ }^{167}$ Art. 47 C.Pol. U.R.S.S. 
La Constitución de 1978 de la Rep. Popular China declara: "El Estado asegura la posición dirigente del marxismo-leninismo-pensamiento Mao Tsetung en los diversos dominios de la ideología y la cultura. Todas las instituciones culturales deben servir a los obreros, campesinos y soldados y ponerse al servicio del socialismo". ${ }^{168}$

La reciente Constitución cubana de 1992 en el capítulo titulado "EDUCACION Y CULTURA" puntualiza que el Estado "fundamente su política educacional y cultural en los avances de la ciencia y la técnica, el ideario marxista y martiano, la tradición pedagógica progresista cubana y la universal". Añade que el Estado promueve "la educación patriótica y la formación comunista de las nuevas generaciones y la preparación de los niños, jóvenes y adultos para la vida social". Declara que "es libre la creación artística siempre que su contenido no sea contrario a la Revolución". Y asegura que "la actividad creadora e investigadora en la ciencia es libre" 169

Cualquiera acción compulsiva de un gobierno que impone su ideología como verdad oficial, negando todo espacio a las creencias discrepantes, apaga o sofoca la libertad de cátedra con grave detrimento de la creación cultural y del desarrollo educativo.

En 1875, siendo el Marqués de Orovio, Ministro responsable de la instrucción pública, dictó una célebre Circular que conmocionó el mundo académico español.

"En el orden moral y religioso -decía la Circular, dirigida a los Rectores de las Universidades- invocando la libertad más absoluta, se ha venido a tiranizar a la inmensa mayoría del pueblo español, que siendo católica, tiene derecho, según los modernos sistemas políticos, fundados precisamente en las mayorías, a que la enseñanza oficial que sostiene y paga esté en armonía con sus aspiraciones y creencias... Cuando la mayoría y casi la totalidad de los españoles es católica y el Estado es católico, la enseñanza oficial debe obedecer a este principio, sujetándose a todas sus consecuencias. Partiendo de esta base, el Gobierno no puede consentir que en las cátedras sostenidas por el Estado se explique contra un dogma que es la verdad social de nuestra Patria. Es, pues, preciso que vigile V.S. con el mayor cuidado que en los establecimientos que dependen de su autoridad no se enseñe nada contrario del dogma católico ni a la sana moral, procurando que los profesores se atengan estrictamente a la explicación de las asignaturas que les están confiadas, sin extraviar el espíritu dócil de la juventud por sendas que conduzcan a funestos errores sociales... Por ningún concepto tolere que en los establecimientos dependientes de este Rectorado se explique nada que ataque directa ni indirectamente a la Monarquía constitucional ni al régimen político, casi unánimemente proclamado por el país... Si desdichadamente V.S. tuviera noticias de que alguno no reconociera el régimen establecido o explicara contra él, proceda sin ningún género de consideración a la formación del expediente oportuno".

Por fortuna, a las prescripciones de esta Circular se opuso la flor y nata de la intelectualidad de la época: Giner, Azcárate, Salmerón, González Linares, Castelar, Calderón, Moret y otros. Monteros Ríos, titular de la cátedra de Derecho Canónico de la

${ }^{168}$ aRT. 14 C. Pol. china

${ }^{169}$ Art. 39 C. Pol. cubana. 
Universidad Central, renunció a ella en defensa de la libertad de cátedra; hasta que el gobierno Cánovas tuvo que derogar la ominosa Circular. ${ }^{170}$

Siendo el Profesor Rocco Ministro de Asuntos Culturales del Gobierno de Mussolini, se invitó a los académicos y científicos italianos a suscribir un juramento de fidelidad al sistema fascista. Le escribió, entonces, desde la Universidad de Berlín, el Profesor Albert Einstein, instándole a "ahorrar esta humillación a los representantes de la Ciencia". Le decía en su carta: "Por muy diferentes que sean nuestras opiniones políticas, estoy convencido de que al menos en un punto fundamental estamos de acuerdo: ambos consideramos el desarrollo espiritual europeo como uno de nuestros bienes más importantes. Este se basa en la libertad de opinión y de enseñanza, y en el axioma de que la búsqueda de la verdad se ha de anteponer a todas las demás".

Y añadía más adelante: "Lejos de mis propósitos está dicutir con usted las intromisiones en la libertad por parte de hombres que pueden jusificarse con razones de Estado. Pero la búsqueda de la verdad científica... tendría que ser sagrada para el poder estatal; y es de gran interés para todos el que los Servidores de la Verdad no sean molestados". ${ }^{171}$

Durante el Régimen Militar, las Universidades chilenas sufrieron la dolorosa mutilación de sus dos grandes prerrogativas: la autonomía universitaria, cercenada por la intervención militar de los Rectores Delegados; y la libertad académica, amagada por exoneraciones masivas de profesores que, a veces, significaron la desaparición de Escuelas, Facultades, Institutos y equipos completos de investigación científica.

Nuestra Universidad tuvo la suerte de ser regida, desde su fundación, por Rectores escogidos entre sus propios docentes, que morigeraron en gran medida el rigor que otras debieron padecer. Debemos fortalecer y velar por el rigor de nuestra libertad académica, para que una coyuntura tan aciaga jamás vuelva a repetirse.

En materia de libertad de cátedra, se acostumbra distinguir entre la libertad de enseñar y el derecho a educar, no obstante que ambos se ejercen simultáneamente.

Siendo la enseñanza la transmisión sistemática que hace el profesor de un conjunto de conocimientos, su libertad consiste en que está facultando para decidir la forma o método, el contenido o sustancia del conocimiento que imparte y el caudal de información que estime adecuado y suficiente.

En cambio, el derecho de educar, que requiere una aptitud personalísima del educador, consiste en la facultad de exponer, como verdadera, la convicción del maestro y conlleva su intención de imprimir una determinada formación en el alumno; sin perjuicio de respetar las limitaciones a esta libertad, que ya dejamos señaladas, y la propia libertad de aprendizaje del educando.

En concreto, la libertad de cátedra permite:

${ }^{170}$ Vid. Tomás R. FERNANDEZ: "La Autonomía Universitaria" (Sobre la libertad de Cátedra), Civistas, Madrid, 1982.

${ }^{171}$ Albert EINSTEIN: "Mi visión del Mundo" ("Mein Weltbild"); Tusquets Editores, Barcelona, 1981; pg. 27. 
a) Exponer, objetivamente, todas las teorías alternativas sobre cualquiera materia del programa, incluyendo las contrarias o divergentes del sistema imperante y del ideario de la propia Universidad.

b) Enseñar la propia teoría o posición del maestro frente a las doctrinas expuestas.

c) Educar al alumnado en la dirección que el profesor considere correcta. La educación universitaria implica la formación de una conciencia crítica que habilite al estudiante para formular su propio juicio frente a la realidad y frente al propio maestro.

d) Abrir debate sobre una materia o punto controvertido con respecto a la más amplia libertad de expresión por parte de los alumnos;

e) Emplear sistemas participativos -como el denominado "clase activa"- con respecto a la libertad académica de los participantes.

\section{LIBERTAD DE INVESTIGACION}

Esta forma de libertad resulta más fácil de describir, en términos negativos, por la ausencia de trabas que debe caracterizarla.

Naturalmente, puede ocurrir que la situación económica -generalmente deficitariade la Universidad, o los requerimientos científicos y tecnológicos del medio circundante, aconsejen u obliguen a orientar la investigación en un área o en un sentido determinado.

Lo importante es que no se fuerce al investigador a asumir una labor que no desea ni le interesa; esto es, que su oferta a la demanda de investigación -si es que existe una demanda específica- sea libremente consentida. Que pueda elegir y variar, dentro de alternativas razonables y posibles, tanto los métodos como la dirección de su tarea.

Que no haya vetos frente a caminos que el propio desarrollo de la investigación desbroce. Son innumerables los descubrimientos científicos que han surgido de la exploración de vías accidentalmente abiertas en el curso de una investigación. Y muchas veces, un proyecto encaminado en determinada dirección, ha concluido en resultados distintos, tan sorprendentes para el investigador como positivos para el desarrollo de la ciencias.

Esto no habría sido posible sin la libertad de investigar, ese bálsamo de que disponen los pocos privilegiados que padecen la bendita urticaria del afán investigador.

En resumen, la libertad de investigación supone la autoría o la libre adhesión al proyecto respectivo; la facultad de cancelar o de suspender una investigación que, presumiblemente, no llegará al resultado propuesto. $Y$ supone, también, que el investigador se sienta libre, esto es, se sienta exento de presiones y de compulsiones, tanto por parte del Estado como de la propia Universidad, frente a la investigación que acomete.

\section{LIBERTAD DE APRENDIZAJE}

Es ésta, propiamente, la libertad académica del estudiante.

La Constitución portuguesa la garantiza, genéricamente, como "libertad de aprender" (art. 43-1); y en la legislación española se la especifica como "libertad de 
estudio". La Constitución colombiana la singulariza como "libertad de aprendizaje" (art. 27).

Nosotros preferimos esta última designación ya que ella no sólo comporta la facultad de elegir los instrumentos y fuentes de información -que es lo propio de la libertad de estudio- sino también, el ciclo completo que va desde la libertad de elegir carrera pasando por la de elegir profesor cuando existen cátedras paralelas, y la de elegir curriculum cuando éste es flexible y permite varias opciones curriculares- hasta la libertad de expresar, defender y postular eficazmente teorías, doctrinas o posiciones distintas o discrepantes con las enseñadas desde la Cátedra; siempre naturalmente que ellas tengan una fundamentación razonablemente sólida.

Recordemos que la reforma introducida a nuestra Constitución de 1925 por la ley 17.398 de enero de 1971, el art. 10 - N 7 de esa Carta, decía: "Los estatutos universitarios tienen derecho a expresar sus propias ideas y escoger, en cuanto sea posible, la enseñanza y tuición de los profesores que prefieran".

Hemos recalcado que esta libertad, para que realmente exista, debe ser eficaz. Esto es, no basta con que el estudiante pueda opinar durante la clase, dando a conocer su posición frente a determinada materia, y tenga luego que renunciar a sus convicciones al momento de dar sus pruebas o exámenes, como necesaria rendición intelectual que le permite progresar en sus estudios.

Esto no sólo sería una parodia de libertad, sino más bien reflejaría una denegación de ella. No puede forzarse a un estudiante a repetir en voz alta lo que escuchó en la Cátedra y resignarle a murmurar en voz baja -como Galileo ante la Inquisición- "y sin embargo, se mueve..."

La libertad académica del estudiante le habilita para aprobar exámenes y grados aun cuando su postura sea discrepante de la de su maestro y del ideario de la Universidad, con la sola condición de que conozca las demás posiciones y tenga -como ya hemos dichorazones bien fundadas para preferir la que sustenta. ${ }^{172}$

Produce fatiga pensar qué hubiera ocurrido con el desarrollo de la Física si con el criterio de autoridad encerrado en la fórmula "Magister dixit", se hubiera reprobado al estudiante Einstein, por contradecir -con una teoría sospechosa desde su nombre- las sólidas leyes de la mécanica de Newton o de la geometría euclidiana.

Y si esta hipótesis es valedera en las llamadas "ciencias exactas" - ¿qué decir de las ciencias humanas donde lo absolutamente cierto es su relatividad?

Concluyamos, en resumen, que la libertad académica del estudiante le habilita -sin perjuicio de la elección del profesor, del tutor y del curriculum, cuando ello es posible- para adherir a cualquier posición alternativa de las enseñadas en la cátedra, aunque no sea la de su maestro, o para asumir su propia posición; para expresar, sin cortapisas, sus ideas, aun cuando ellas discrepen de las impartidas en la Cátedra o del Ideario de la Universidad; y

${ }^{172}$ Recientemente, hemos confirmado con nota máxima (7) una Memoria de Prueba para optar al grado de Licenciado en Derecho, no obstante discrepar con las tesis planteadas por los postulantes, respetando su libertad académica y calificando así la calidad intelectual de la fundamentación de aquéllas y la capacidad creativa de las egresadas. 
para postular válida y eficazmente sus propias teorías o posturas en las distintas pruebas calificatorias de su aptitud para progresar en el curso de su carrera, hasta terminarla.

\section{RESPONSABILIDAD DE LA LIBERTAD DEL MAESTRO}

La libertad Académica constituye más una responsabilidad que un derecho más una atadura que un desprendimiento; una servidumbre, más que un señorío.

1. El compromiso de la verdad.- Destaca en "La Odisea" del fabuloso Homero, el episodio de Ulises, aproximándose en su embarcación a la isla de las Sirenas. La voluntad de Ulises consiste en regresar a Itaca y a los brazos de Penélope. Sabe que su embarcación naufragará si él se deja seducir por los cantos de las Sirenas. Y entonces, para preservar su libertad de llegar donde quiere, se hace atar al mástil de su barco, tapa sus oídos con cera y sólo así, consigue que su libertad prevalezca.

El primer deber del universitario, particularmente cuando hace uso de la L.A., es atarse y someterse a la tiranía de la verdad. Más aún: es ésa la única tiranía a la que el universitario tiene el deber de servir. Ya lo dijo el Prof. EINSTEIN: no debe molestarse a los Servidores de la Verdad...

Porque ante la Verdad, nadie es libre; ni para desconocerla ni para esquivarla.

Nada valen, ante ella, los cantos de sirena de las "nuevas olas" intelectuales, ni las teorías deslumbrantes pero huecas, ni los juegos de pirotecnia retórica que surgen a menudo en el abigarrado tránsito de las ideas.

Así como en el militar la cualidad fundamental es la valentía, que le hace abnegar su propia vida, así en el universitario la virtud definitoria es su amor por la verdad, a la que debe abnegar - llegado el caso- su propia condición universitaria.

Un académico que no sea capaz de luchar -con todas sus consecuencias- por el imperio de la verdad, o que carezca de la valentía necesaria para reconocer sus errores, no es digno de estar en la Universidad.

Esta posición, que parece fácil de discernir en la teoría, resulta increíblemente fatigosa en la realidad. No es la verdad científica, y mucho menos la verdad artística y. tal vez menos aún, la verdad de las ciencias humanas y de la filosofía, una luz resplandeciente que emerja nítida, ahuyentando las sombras.

Por el contrario, la verdad científica es delgada como el filo de la navaja; equívoca, como las formas que aparecen al retirarse la niebla; difícilmente discernible, como las llamas de una chimenea que se sabe que están allí porque se siente su calor y su presencia, pero cuya constante mudanza dificulta fijarla y reproducirlas. Esto, cuando no ocurre con la verdad lo que dijo el poeta sobre el cielo: "... porque ese cielo azul que todos vemos / ni es cielo ni es azul; jlástima grande/ que no sea verdad tanta belleza!"

De allí que la libertad académica también obliga a un permanente afán de búsqueda, de descubrimiento, de perfilación progresiva de las verdades que el académico profesa, sin que pueda jamás asilarse y anquilosarse en el ciclo de lo repetitivo.

Wayne W. Dyer ha señalado que un profesor con treinta años de docencia debe preguntarse si ha repetido un año de clases treinta veces o si, en verdad, ha hecho progresar su clase, cada vez, durante treinta años. 
2. La honradez intelectual.- En otro importante aspecto, la libertad académica obliga a ser honesto con el pensamiento ajeno.

Esta honestidad -que no es sino una faceta particular de la ética de la libertad y del compromiso de ésta con la verdad- presenta dos aspectos relevantes.

Consiste, el primero, en no desfigurarse ni minimizar el pensamiento ajeno -a pretexto de que el error carece de derechos- y con el inconfesable propósito de rebatirlo más fácilmente, o mediante argumentos que no tendrían la misma fuerza ni eficacia, si la teoría, doctrina o posición que se impugna fueran expuestos -como debe ser- con toda su base argumental y con todo su montaje dialéctico.

No es libertad académica, sino fraude intelectual, aquella práctica -por desgracia no infrecuente en algunos medios y disciplinas- de acomodar el banco de la doctrina que se combate al calibre y fuerza destructiva de las armas -a veces menguadas- de que el expositor dispone para rebatirla.

Por el contrario, un verdadero académico, debe conocer y valorar a fondo lá teoría sujeta a impugnación. Como un ajedrecista que juega una partida solitaria, debe alinear las piezas contrarias y moverlas en el tablero con la mayor destreza posible. $Y$ sólo entonces, cuando haya sabido rendir los honores debidos al adversario ausente, su posición crítica habrá adquirido la dignidad propia de la estatura académica.

Un segundo aspecto de la honestidad intelectual concierne a la paternidad de las ideas y de las citas.

El plagio -que puede ser pecado habitual en algunas artes- no debe admitirse ni perdonarse nunca en la Universidad. $Y$ este rigor debe alcanzar tanto al maestro como al estudiante.

Presentar teorías ajenas como propias, copiar párrafos o citas, transcribirlos sin las consabidas comillas indicando su autor y procedencia, son conductas que deben aborrecerse - $y$, su aborrecimiento, inculcarse- como una defraudación deshonrosa.

Alguien decía que el conocimiento humano es como una pirámide multitudinaria de seres en que los últimos que llegan a la cima han trepado sobre las espaldas de todos los que llegaron antes.

Pues bien, todos estos peldaños que nos han sido útiles para escalar el nivel de nuestro conocimiento tienen su nombre y reclaman el derecho a que su contribución se reconozca y no sea saqueada a mansalva, como ocurre con los plagiarios.

3. Respeto intelectual al estudiante.- Un tercer aspecto del compromiso con la verdad se expresa en la honestidad intelectual debida a nuestros discípulos.

Ningún profesor tiene la obligación de ser un erudito ni un artefacto nemotécnico. $Y$ si un estudiante nos formula una pregunta intempestiva en una materia en que no estamos preparados, no es honesto improvisar una respuesta con riesgo de equivocación, ni eludir la interrogante desviándonos del tema.

El peor recuerdo, de este orden, que guardo de mis tiempos de estudiante es el gran agudo compañero que descubrió un error evidente en la exposición del profesor, y se lo hizo notar. Como no fuera la primera vez que esto ocurría, el profesor, en lugar de rectificarse, 
visiblemente alterado le reconvino: "No vuelva a interrumpirme. Detesto a la gente que se dedica a cazar gazapos".

Existe en algunas universidades la costumbre de asociarse a los alumnos a las investigaciones o a la producción editorial de sus maestros. Esto sería encomiable, si no fuese porque algunos profesores omiten, a veces, reconocer la autoría o la colaboración de sus ayudantes en sus obras; $y$, en esa forma, se apropian indebidamente de su trabajo intelectual de una manera que se diferencia del plagio sólo por practicarse a la vista, conciencia y paciencia de sus víctimas.

Ojalá esta costumbre -a nuestro juicio corruptora, además de corrupta- no adquiera jamás ni siquiera permiso de residencia temporal en nuestra Universidad.

4. Libertad académica y humildad intelectual.- La L.A., debe, por último, rendir tributo a la humildad. $Y$ debe hacerlo, porque ésta no es sino un requerimiento de la verdad y de la justicia.

Cuando un profesor, en un acto de humildad, reconoce el error que puede haber cometido, no está sino demostrado su amor a la verdad que le induce a rectificarlo y su respeto por la justicia que le obliga a restablecer el imperio de aquélla, en un acto expiatorio en que implícitamente se declara culpable

Es necesario pregonar con insistencia la obligación de todo universitario de pagar este tributo del que muchos académicos se sienten justificados evasores.

Por lo común de nuestro medio es justamente lo contrario: la soberbia intelectual. Esa óptica deformante que nos hace percibir nuestras obras como fruto exclusivo de nuestra asombrosa capacidad creativa y originalidad; olvidando que sólo hemos recolectado o puesto en una perspectiva diferente $y$, a lo sumo, agregado una pizca, al material acumulado en siglos de conocimiento y decantación. Esa misma deformación visual nos lleva a menospreciar -como un catalejo puesto al revés- las contribuciones intelectuales de nuestros colegas.

De la misma manera que a los centuriones romanos que regresaban victoriosos a la capital del Imperio, nos hace falta a los académicos -en la embriaguez que sigue a nuestras modestas creaciones- la presencia de una auriga que nos repita constantemente al oído: "Acuérdate que eres mortal".

\section{RESPONSABILIDAD DEL ESTUDIANTE UNIVERSITARIO}

Tres responsabilidades asume el estudiante desde su ingreso a la Universidad. Ellas conciernen a la familia de que forma parte, a la propia Universidad y a la Sociedad en que ésta se inserta.

Cada estudiante es deudor de una carga de sacrificios acumulados durante dieciocho años -que en muchos casos, han pesado sobre los hombros de sus padres como la cruz sobre la espalda de Cristo- para hacer posible su formación profesional. Esta deuda que algunos olvidan retribuir después que reciben el título- merece, al menos, la certeza que debe darse a la familia que sus esfuerzos y esperanzas no fueron prodigados en vano.

Por otra parte, ingresar a la Universidad constituye un previlegio que no puede desperdiciarse. Detrás de cada puesto de estudio yacen las penurias y frustraciones de 
quienes no pudieron entrar o no pudieron permanecer en la Universidad. En las puertas de ésta se cumple la sentencia evangélica que nos recuerda que "Muchos son los llamados y pocos, los escogidos". Por eso, ningún estudiante tiene derecho a malgastar la oportunidad excepcional de que disfruta y que le fue negada a muchos otros, ni desertando de la Universidad en el curso de la Carrera, ni desertando de la profesión después de obtenido su título.

Por último, cada universitario debe asumir su deuda con la Sociedad. Dejaremos a un lado el costo sideral que al Estado chileno significa la formación de cada profesional, porque no estamos hablando de deudas dinerarias.

Las profesiones no son sólo el modo de ganarse el sustento y ascender socialmente. Son, antes que nada, el medio especializado de atender las necesidades sociales. La justicia, la educación, la salud, las obras públicas, la explotación de los recursos naturales, en fin, el objeto de cada profesión es resolver los problemas que a la sociedad se le presenta en cada área. Esta necesidad exige una buena formación profesional. Y quien no logra con los medios que la Universidad le proporciona, defrauda a su familia, defrauda a la Universidad y defrauda a la Sociedad.

Por eso es que Uds., estudiantes universitarios, les recomiendo cumplir sólo tres deberes: primero, estudiar; segundo, estudiar más; y tercer lugar, estudiar más aún. Y después de cumplidos estos tres deberes pueden pensar en cómo utilizar provechosamente el tiempo libre.

\section{VALOR Y TRASCENDENCIA DE LA LIBERTAD ACADEMICA}

Después de dibujar los contornos limitantes de la Libertad Académica, cabe preguntarse: ¿qué tiene ella, entonces, de atractivo que tantos la defienden y tantos la añoran?

Ocurre con la libertad lo que sucede con el aire. Siendo éste una cosa vital, no se le ve, no se le siente, ni siquiera se advierte que está allí. Simplemente se le respira: y respirándole, se hace posible la vida, el sueño, el trabajo y el reposo.

El aire, paradojalmente, así como la libertad, comparece en la conciencia en el instante mismo en que se ausenta del ambiente. Es el aire viciado, es la falta de aire, la que nos descubre, de golpe, la necesidad de aire puro.

Pero a diferencia del aire, la libertad académica debe estar allí -en el ámbito de la Universidad- aunque no la utilicemos. Porque ella, para el universitario, es como el cielo abierto para el ave, que le invita a volar sin temor y sin impedimientos; pero que no le obliga a permanecer todo el tiempo volando.

La L.A. es la paz espiritual, exenta de toda compulsión y de toda amenaza, que permita y provoca la chispa de la creación en toda su magnificiencia.

Las grandes teorías, las portentosas doctrinas que han conmovido y que aun conmueven al mundo -incluso en aquellos países en que hoy no existe ni se la respetanacieron y pudieron desarrollarse gracias a la libertad intelectual.

Y no nos mueva a engaño el hecho de que en alguno de esos países, en que la Universidad es un servicio exclusivo del Estado y la libertad académica no existe, hayan 
podido surgir gigantes como un Solyhenitzin en la Literatura o un Shakharov en la Ciencia. Porque así como Tomás Moro fue más libre de espíritu en la cárcel que su propio carcelero, el Rey Enrique VIII, así también esos hombres y algunos otros seres superiores han sabido ejercitar su voluntad y su intelecto en un espacio de libertad abierto por ellos mismos. $Y$ ha sido esa libertad y no su negociación regimentada, la que ha hecho posible su actividad creadora.

Sin libertad académica, la vida universitaria se marchita, como una planta privada de sol.

Sin libertad, es el temor el que invades los espacios abandonados por el entusiasmo creativo; y el temor ni siquiera es concebible en la aventura maravillosa de la búsqueda de la verdad.

Sin libertad, la creación intelectual $-y$, sobre todo, la artística- se atrofian o se apagan. Allí están, para comprobarlo, las raquíticas muestras del realismo soviético o el decaimiento planfletario del teatro chino a raíz de la Revolución Cultural.

Sin libertad, el letargo se apodera de la Universidad. Se cercena la dimensión más noble del maestro: la del educador: y éste, obligado a sobrevivir en el sistema, se atrincha en la condición de funcionario.

Sin libertad, desaparece el ingrediente esencial que dio origen, vitalidad y transcendencia a la Universidad como creación y soporte de la cultura occidental.

Porque desde las primeras Universidades medievales donde eran los estudiantes quienes escogían a sus maestros y designaban a su rector, la libertad académica y la autonomía han sido consubstanciales a la Universidad; de tal manera que negarle aquéllas sería como privar a un halcón de sus dos alas.

Colegas: os invito a respirar a todo pulmón el aire puro de al libertad académica que oxigena el espíritu y estimula la renovación del saber. de plenitud.

Queridos estudiantes: os invito a convertir vuestro paso por esta Casa en un motivo

La vida universitaria será la etapa más hermosa e inolvidable de vuestras vidas.

La vida universitaria es alegre, pero esa alegría no pasa por la mortificación de vuestros compañeros ni de nadie. Vuestra alegría debe ser la manifestación gozosa de vuestro equilibrio interior.

La vida universitaria es estudio, pero éste no debe transformarse en suplicio. La disciplina del estudio puede y debe ser compartida con la recreación, el ejercicio corporal, la comunión con la naturaleza, la meditación, la contemplación y, en fin, el desarrollo del espíritu.

La vida universitaria es un diálogo de valores compartidos entre iguales. De allí surgen las mejores amistades. Os aseguro que la que cultivéis aquí perdurarán toda la vida. En ese diálogo aprenderéis a ejercitar cualidades como la lealtad, la abnegación, la honestidad, la solidaridad, el respeto a las ideas y a la dignidad de los demás. Muchos de los profesores que hoy compartimos con vosotros esta bienvenida, somos amigos desde nuestra época de estudiantes; y tal vez sea ése uno de los lazos más sólidos que nos congrega junto a esta Universidad. 
La vida universitaria es una aventura impredecible. Cada generación debe descubrir el rol que le tiene reservado la historia. Yo os invito a vivir esta aventura con toda la energía, del idealismo y la esperanza que vuestra juventud sea capaz de consagrar a una tarea tan noble.

Existe una antigua exhortación del poeta Horacio en su oda Ad Ligurium: "Carpe diem": aprovecha el día. Ella fue rescatada por los poetas del Renacimiento y, en fecha reciente, se la ha revivido en un filme británico, "La Sociedad de los Poetas Muertos". Yo os invito a escuchar al poeta Horacio; a hacer de vuestra vida universitaria una aventura digna de ser vivida.

¡CARPE DIEM!; sacad el fruto a cada hora de vuestra vida. 